\title{
Oral health in the analysis of patients with hearing disabilities
}

\section{Saúde bucal na análise de pacientes com deficiência auditiva}

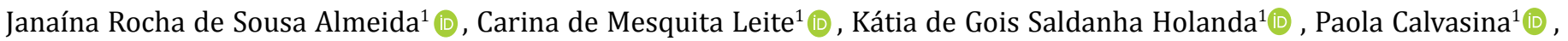 \\ Jéferson Martins Pereira Lucena Franco ${ }^{2,3}$ [D, Paulo Goberlânio Barros Silva ${ }^{3}$ (D)
}

1. Department of Dental Clinic, Christus University Center (UNICHRISTUS), Fortaleza, Ceará, Brazil. 2. Division of Oral and Maxillofacial Surgery, Postgraduate Program in Dentistry, Christus University (UNICHRISTUS), Fortaleza, Ceará, Brazil. Professor, Division of Oral and Maxillofacial Surgery, Doctor Leão Sampaio University Center (UNILEÃO), Juazeiro do Norte, Ceará, Brazil. 3. Department of Dental Clinic, Christus University Center and Division of Oral and Maxillofacial Surgery, Fortaleza General Hospital; Christus University Center, Ceará, Fortaleza, Ceará, Brasil.

\begin{abstract}
Objective: To assess the degree of knowledge of deaf and hard of hearing patients about oral health and relate it to clinical and demographic variables. Methods: The target population was schoolchildren from the 6th to the 9th grade of Elementary School and the 1st year of High School. Data collection took place through a structured questionnaire previously validated. The expressed as absolute and percentage frequencies it was analyzed using Fisher's exact test or Pearson's chi-square test $(\mathrm{p}<0.05)$. Results: Assessing the relationship between oral health and quality of life, to 53 students, $32.1 \%$ of students never reported pain in their teeth, mouth, or jaws, 55.8\% never missed school due to problems with their teeth or dental treatments, $71,2 \%$ never avoided smiling or laughing due to problems with teeth or dental treatments, 53.8\% never avoided opening their mouths or talking due to problems with teeth or dental treatments. Conclusion: Professional and patient communication should be emphasized with the deaf and hard of hearing to intensify the importance of monitoring with the dental surgeon, carrying out activities to promote, prevent, cure, and rehabilitate oral health.
\end{abstract}

Keywords: Community Dentistry; Hearing Loss; Oral Health.

\section{Resumo}

Objetivo: Avaliar o grau de conhecimento de pacientes portadores de deficiência auditiva sobre a saúde bucal, e relacionar com as variáveis clínicas e demográficas. Métodos: A população alvo foram escolares do 6o ao 9o ano do Ensino Fundamental e do 1ํano do Ensino Médio. A coleta de dados ocorreu de agosto a novembro de 2018, por meio de um questionário estruturado previamente validado. A análise dos dados foi realizada por meio do programa SPSS (Statistical Package of the Social Sciences) e expressos em forma de frequência absoluta e percentual e analisados pelo teste exato de Fisher ou quiquadrado de Pearson $(\mathrm{p}<0,05)$. Resultados: Avaliando a relação da saúde bucal com a qualidade de vida de 53 alunos; $32,1 \%$ dos alunos nunca relataram dores nos dentes, na boca, ou nos maxilares, 55,8\% nunca faltaram à escola devido problemas com os dentes ou tratamentos dentários, $71,2 \%$ nunca evitaram sorrir ou rir devido a problemas com os dentes ou tratamentos dentários, 53,8\% nunca evitaram abrir a boca ou falar devido a problemas com os dentes ou tratamentos dentários. Conclusão: A comunicação profissional e paciente deve ser enfatizada com os portadores de deficientes auditivos, com o intuito de intensificar a importância do acompanhamento com o cirurgião dentista, realizando atividades de promoção, prevenção, cura e reabilitação à saúde bucal.

Palavras-chave: Odontologia Comunitária; Perda de Audição; Saúde Oral.

INTRODUCTION

Hearing loss is a type of sensory deprivation, in which the common symptom is an abnormal reaction to the sound stimulus. Because it is considered different from the normal, being included in the discrimination of any other disability, depriving the bearer of some social life, making them go after people "equal" to them and stay away from hearing people and their citizenship rights, among they the right to comprehensive health care ${ }^{1-3}$.

The characterization of hearing loss is varied. Individuals who have mild or moderate deafness and severe or profound deafness are considered "partially deaf" and "deaf". Patients with "mild deafness" have a hearing loss of up to 40 decibels, preventing the individual from equally perceiving all phonemes of words, but it does not prevent regular language acquisition.
Those with "moderate deafness" have hearing loss between 40 and 70 decibels. There is frequent language delay, with, in some cases, more serious linguistic problems, identifying more significant words, presenting difficulty in understanding other terms of relationship and grammatical phrases ${ }^{2-5}$.

The individual considered deaf who presents "severe deafness" has hearing loss between 70 and 90 decibels, perceives strong and known sounds. Their verbal understanding will depend, mainly, on the individual's ability to use visual perception and observe the context of the situations. On the other hand, which presents "profound deafness", hearing loss is higher than 90 decibels and prevents the individual from perceiving and identifying the human voice, making it impossible for them to acquire oral language $\mathrm{e}^{6-10}$. 
Dental surgeons have an essential task since the intention to communicate with patients with hearing loss must find ways to achieve this approach. Thus, more information is needed outside the area of expertise to acquire essential knowledge to relate and solve local and systemic problems $\mathrm{s}^{3-5}$.

Considering the scarcity of studies on oral health in patients with hearing loss and understanding the importance of this information for the implementation of inclusive oral health policy, the objective of this article is to know the perception of oral health in the analysis of adolescents with hearing loss.

\section{METHODS}

This observational, quantitative, and cross-sectional study evaluated students at a school for students with hearing impairment, which is in the city of Fortaleza, Ceará, Brazil, from August to November 2018, through a structured question bank. The study population consisted of students from the 6th to the 9th grade of Elementary School and the 1st year of High School. The study included students who did not have cognitive impairment and, therefore, were able to answer a structured questionnaire. A total of 53 questionnaires were included in the survey; a questionnaire was excluded for not presenting all the questions answered.

The students received the Assent Form and Informed Consent Form (ICF) and took them home, intending to request the authorization of those responsible for participating in the study. After returning the terms, the questionnaires were applied. The application was carried out in the morning, with students from the 6th and 7th year of Elementary School, and in the afternoon with students from the 8th and 9th year of Elementary School, and the 1st year of High School. The activity took place in the school auditorium, through the projection of a video, it was built by the school's interpreters, under the supervision of a researcher in that study. The video presented the interpretation in pounds of the questions contained in the questionnaire so that students could better understand the same.

Data were exported from Microsoft Excel to the software Statistical Package for the Social Sciences (SPSS) version 20.0 for Windows, expressed as absolute and percentage frequencies, and analyzed using Fisher's exact test or Pearson's chi-square test $(p<0.05)$

\section{Ethics approval / Patient's permission}

The patient's permission was obtained. This research was submitted to and approved by the Research Ethics Committee of the Centro Universitário Christus (Unichristus) under protocol number 2,758,782.

\section{RESULTS}

A total of 53 students met the research eligibility criteria, 24 of them female $(45.3 \%)$ and 29 males (54.7\%), 32 students aged up to 16 years, and 21 over 16 years old. The impact of oral health on quality of life, $32.1 \%(n=17)$ never reported pain in the teeth, mouth, or jaws, $55.8 \%(n=29)$ never missed school due to problems with teeth or dental treatments, $71.2 \%$ ( $n=$ 37) never avoided smiling due to problems with teeth or dental treatments, 53.8\% $(n=28)$ never avoided opening their mouths or talking due to problems with teeth or dental treatments. (Table 1).

Table 1. Characterization of deaf and hard of hearing adolescents and analysis of their perceptions about oral health, Fortaleza-2018.

\begin{tabular}{|c|c|c|}
\hline Variables & $\mathrm{n}$ & $\%$ \\
\hline \multicolumn{3}{|l|}{ Sex } \\
\hline Female & 24 & 45.3 \\
\hline Male & 29 & 54.7 \\
\hline \multicolumn{3}{|l|}{ Age } \\
\hline Up to 16 years old & 32 & 60.4 \\
\hline Over 16 years old & 21 & 39.6 \\
\hline \multicolumn{3}{|l|}{ Has had tooth pain } \\
\hline Never & 17 & 32.1 \\
\hline Hardly ever & 12 & 22.6 \\
\hline Sometimes & 19 & 35.8 \\
\hline Frequently & 1 & 1.9 \\
\hline Highly frequently & 1 & 1.9 \\
\hline I don't know & 3 & 5.7 \\
\hline \multicolumn{3}{|c|}{ Has missed school due to problems with teeth or dental treatments } \\
\hline Never & 29 & 55.8 \\
\hline
\end{tabular}




\begin{tabular}{|c|c|c|}
\hline Variables & $\mathbf{n}$ & $\%$ \\
\hline Hardly ever & 11 & 21.2 \\
\hline Sometimes & 10 & 19.2 \\
\hline Frequently & 1 & 1.9 \\
\hline Highly frequently & 1 & 1.9 \\
\hline \multicolumn{3}{|c|}{ Has avoided smiling due to problems with teeth or dental treatments } \\
\hline Never & 37 & 71.2 \\
\hline Hardly ever & 3 & 5.8 \\
\hline Sometimes & 10 & 19.2 \\
\hline Highly frequently & 1 & 1.9 \\
\hline I don't know & 1 & 1.9 \\
\hline \multicolumn{3}{|c|}{ Has avoided opening the mouth due to problems with their teeth or dental treatments } \\
\hline Never & 28 & 53.8 \\
\hline Hardly ever & 5 & 9.6 \\
\hline Sometimes & 15 & 28.8 \\
\hline I don't know & 4 & 7.7 \\
\hline \multicolumn{3}{|l|}{ Has been to the dentist } \\
\hline Yes & 48 & 90.6 \\
\hline No & 5 & 9.4 \\
\hline \multicolumn{3}{|l|}{ Last appointment with a dentist } \\
\hline Between 6 months and 1 year & 14 & 28.0 \\
\hline Between 1 and 2 years & 18 & 36.0 \\
\hline Over 2 years & 18 & 36.0 \\
\hline \multicolumn{3}{|l|}{ Going to the dentist is } \\
\hline Very nice & 10 & 20.0 \\
\hline Nice & 10 & 20.0 \\
\hline Required & 25 & 50.0 \\
\hline Unnecessary & 4 & 8.0 \\
\hline Bad & 1 & 2.0 \\
\hline \multicolumn{3}{|c|}{ Feelings regarding going to the dentist } \\
\hline Joy & 20 & 40.0 \\
\hline Love & 5 & 10.0 \\
\hline Happiness & 6 & 12.0 \\
\hline Affection & 11 & 22.0 \\
\hline Fear & 7 & 14.0 \\
\hline Other & 1 & 2.0 \\
\hline \multicolumn{3}{|l|}{ Needs dental treatment } \\
\hline Yes & 20 & 38.5 \\
\hline No & 13 & 25.0 \\
\hline I can't say & 19 & 36.5 \\
\hline \multicolumn{3}{|l|}{ How do you rate your oral health } \\
\hline Great & 9 & 17.3 \\
\hline Good & 32 & 61.5 \\
\hline Regular & 9 & 17.3 \\
\hline Bad & 2 & 3.8 \\
\hline Awful & 0 & 0 \\
\hline
\end{tabular}


Of the 53 students, $90.6 \%(n=48)$ have already been to the dentist, $36 \%$ ( $n=18$ ) were last between 1 and 2 years old, and over 2 years, $50 \%(n=25)$ replied that going to the dentist is a necessary situation. Feelings related to oral health showed that $40 \%(n=20)$ of the interviewees remember the dentist's consultation with joy. Regarding the self-reported dental needs of adolescents with hearing loss, 38.5\% ( $n=20$ ) responded that they need to undergo dental treatments. Self-perception of oral health was assessed as good by $61.5 \%(n=32)$ of the participants. (Table 1).

When performing the bivariate analysis with the dependent variable, how you classify your oral health, and the other variables, it was observed that there was no statistical correlation between them. (Table 2).

Table 2. Bivariate assessment between the classification of self-reported oral health by adolescents with hearing loss and the other variables, Fortaleza-2018.

\begin{tabular}{|c|c|c|c|c|c|}
\hline \multirow{2}{*}{ Sex } & \multicolumn{4}{|c|}{ How do you rate your oral health } & \multirow[b]{2}{*}{ p-Valo } \\
\hline & \multicolumn{2}{|c|}{ Great/Good } & \multicolumn{2}{|c|}{ Regular/Bad/Awful } & \\
\hline Female & 19 & $46.3 \%$ & 4 & $36.4 \%$ & 0.554 \\
\hline Male & 22 & $53.7 \%$ & 7 & $63.6 \%$ & \\
\hline \multicolumn{6}{|l|}{ Age } \\
\hline Up to 16 years old & 24 & $58.5 \%$ & 7 & $63.6 \%$ & 0.760 \\
\hline Over 16 years old & 17 & $41.5 \%$ & 4 & $36.4 \%$ & \\
\hline \multicolumn{6}{|l|}{ Has had tooth pain } \\
\hline Never & 11 & $26.8 \%$ & 5 & $45.5 \%$ & 0.224 \\
\hline Hardly ever & 11 & $26.8 \%$ & 1 & $9.1 \%$ & \\
\hline Sometimes & 15 & $36.6 \%$ & 4 & $36.4 \%$ & \\
\hline Frequently & 1 & $2.4 \%$ & 0 & $.0 \%$ & \\
\hline Highly frequently & 0 & $.0 \%$ & 1 & $9.1 \%$ & \\
\hline I don't know & 3 & $7.3 \%$ & 0 & $.0 \%$ & \\
\hline \multicolumn{6}{|c|}{ Has missed school due to problems with teeth or dental treatments } \\
\hline Never & 20 & $50.0 \%$ & 8 & $72.7 \%$ & 0.694 \\
\hline Hardly ever & 9 & $22.5 \%$ & 2 & $18.2 \%$ & \\
\hline Sometimes & 9 & $22.5 \%$ & 1 & $9.1 \%$ & \\
\hline Frequently & 1 & $2.5 \%$ & 0 & $.0 \%$ & \\
\hline Highly frequently & 1 & $2.5 \%$ & 0 & $.0 \%$ & \\
\hline \multicolumn{6}{|c|}{ Has avoided smiling due to problems with teeth or dental treatments } \\
\hline Never & 28 & $70.0 \%$ & 8 & $72.7 \%$ & 0.936 \\
\hline Hardly ever & 2 & $5.0 \%$ & 1 & $9.1 \%$ & \\
\hline Sometimes & 8 & $20.0 \%$ & 2 & $18.2 \%$ & \\
\hline Highly frequently & 1 & $2.5 \%$ & 0 & $.0 \%$ & \\
\hline I don't know & 1 & $2.5 \%$ & 0 & $.0 \%$ & \\
\hline \multicolumn{6}{|c|}{$\begin{array}{l}\text { Has avoided opening the mouth due to problems with their teeth or } \\
\text { dental treatments }\end{array}$} \\
\hline Never & 21 & $52.5 \%$ & 6 & $54.5 \%$ & 0.996 \\
\hline Hardly ever & 4 & $10.0 \%$ & 1 & $9.1 \%$ & \\
\hline Sometimes & 12 & $30.0 \%$ & 3 & $27.3 \%$ & \\
\hline I don't know & 3 & $7.5 \%$ & 1 & $9.1 \%$ & \\
\hline
\end{tabular}




\begin{tabular}{|c|c|c|c|c|c|}
\hline \multirow{2}{*}{ Has been to the dentist } & \multicolumn{4}{|c|}{ How do you rate your oral health } & \multirow[b]{2}{*}{ p-Valor } \\
\hline & \multicolumn{2}{|c|}{ Great/Good } & \multicolumn{2}{|c|}{ Regular/Bad/Awful } & \\
\hline Yes & 36 & $87.8 \%$ & 11 & $100.0 \%$ & 0.223 \\
\hline No & 5 & $12.2 \%$ & 0 & $.0 \%$ & \\
\hline \multicolumn{6}{|l|}{ Last appointment with a dentist } \\
\hline Between 1 and 2 years & 14 & $36,8 \%$ & 3 & $27,3 \%$ & \\
\hline Over 2 years & 13 & $34,2 \%$ & 5 & $45,5 \%$ & \\
\hline \multicolumn{6}{|l|}{ Going to the dentist is } \\
\hline Very nice & 6 & $15,4 \%$ & 4 & $36,4 \%$ & 0,242 \\
\hline Unnecessary & 2 & $5,1 \%$ & 2 & $18,2 \%$ & \\
\hline Bad & 1 & $2,6 \%$ & 0 &, $0 \%$ & \\
\hline \multicolumn{6}{|c|}{ Feelings regarding going to the dentist } \\
\hline Joy & 15 & $38,5 \%$ & 4 & $40,0 \%$ & 0,122 \\
\hline Love & 2 & $5,1 \%$ & 3 & $30,0 \%$ & \\
\hline Happiness & 4 & $10,3 \%$ & 2 & $20,0 \%$ & \\
\hline Affection & 11 & $28,2 \%$ & 0 & ,0\% & \\
\hline Fear & 6 & $15,4 \%$ & 1 & $10,0 \%$ & \\
\hline
\end{tabular}

$* p<0.05$, Fisher's exact test or Pearson's chi-square $(n, \%)$.

\section{DISCUSSION}

Dental Surgeons, in addition to having extensive technical and scientific knowledge, need to know a means of communication with their patients. It is important to establish effective communication with the hearing impaired, aiming at better oral health for these patients ${ }^{11,12}$. Blocking communication between the hearing impaired and health professionals represents a significant obstacle for this population. It is observed that nonverbal behavior prevents an effective bond between client and professional, therefore, in its formation, learning the Sign Language is essential ${ }^{8,13}$.

Besides, some studies have observed a higher frequency of oral health problems in individuals with hearing impairments, perhaps due to poor oral hygiene and high levels of periodontal disease when compared to those who do not have these deficiencies. It is emphasized that oral health is part of general health and essential to individuals' quality of life $\mathrm{e}^{1,6}$. Oral health and quality of life have already been shown in some studies. However, despite recognizing the importance of social and psychological aspects in determining the disease, dentistry continues to employ biological indexes in the assessment and determination of treatment needs and the implementation of oral health programs ${ }^{14-16}$.

In the study by Sandeep et al. ${ }^{6}$, according to their interviewees, when looking for dental services, they face situations that negatively interfered with the quality of the communication process. These reported that they experience difficulties in understanding the language of dental professionals who do not master the Sign Language, considered the natural language of the deaf. They also observed that, when deaf patients were asked if they usually go to the dentist, they reported difficulty of access, mainly due to hearing restriction, which is a communicative obstacle in the dental office environment. Most stated that they usually go to the dental office, but need company, reinforcing that the companions go not because of the lack of autonomy, but because they find it challenging to communicate with dental professionals. 
Due to oral health conditions having impacts on people's daily lives, it is urgent to use subjective indicators capable of capturing such impacts, in order to guarantee appropriate assistance policies and strategies ${ }^{17-18}$. Therefore, the social dimensions of oral health and the real impact of health problems on the quality of life of the analyzed individuals and the relevant sociodemographic factors must be considered, since oral health conditions are influenced not only by behavioral habits but also by social issues ${ }^{10}$.

In our study, we observed that a large part of the hearing impaired patients reported having gone to the dentist at least once in their lifetime (90.6\%). It is noteworthy that the evaluated school had a dental office in which children and adolescents were monitored, which certainly favored the high level of access to the dental office. However, it leads us to reflect on why $9.4 \%$ of the interviewees never visited the referred clinic.

Feelings related to the visit to the dental surgeon can be contradictory, and even knowing the importance of monitoring oral health, the feeling of fear can be reported. Anxiety, stress, and pain are often related to dental treatment. Many patients see both psychological stimuli as threats to their well-being, associated with the tendency of negative and threatening thoughts about treatment ${ }^{12-19}$. However, this research analyzed an association of positive thoughts related to dental treatment, in which $40 \%$ of respondents reported feeling joy when going to the dentist, and only $14 \%$ reported feeling afraid. The work focused on the prevention and promotion of oral health has probably contributed to the demystification of dental treatment with the students.

The need for dental follow-up was reported by most participants as well as by many patients with special needs. The dental approach must be based on detailed anamnesis, with all the individual and disability data that will assist in the planning, diagnosis, and prognosis of treatment. Care protocols must be established to prioritize early intervention through preventive measures, and when other procedures are necessary, consideration should be given to the opportunity and the need for treatment6,20. Most deaf and hard-of-hearing adolescents consider their oral health to be good. Several studies have observed a predominance of positive self-perception concerning oral health, which does not necessarily equate to good oral health regarding the clinical aspects of these patients.

Currently, in order to verify the oral health and the need for treatment of patients, in addition to the quantitative data obtained, according to the professional's view, qualitative indicators are used. These are obtained according to the patient's self-perception, thus achieving a more complex perception of each individual's problems with their particularities19. Particular characteristics must be observed; therefore, initially, it is recommended to carry out detailed anamnesis with the parents/guardians or with the interpreter on the causes of deafness. It is noteworthy that there is a relationship between deafness and dental hypoplasia since the development of the auditory nerve occurs in the embryonic period of tooth formation, which can cause changes in the dental structure $\mathrm{e}^{21,22}$. It is important to assess the degree of hearing impairment, because depending on this, there may be a variation in the level of psychomotor and developmental impairment. It is also important to know how the patient's oral hygiene is carried out and guide the person in charge of the importance of attendance in dental appointments.

\section{CONCLUSIONS}

Professional/patient communication should be strengthened in the case of deaf and hard of hearing patients to intensify the importance of these patients' visits to the dental surgeon, and it is necessary to break the block between deaf and health professionals.

Many interviewed patients reported that they considered oral health to be good; however, most mentioned the need for dental treatment. Thus, it becomes relevant to emphasize the need to intensify the monitoring of patients with hearing impairment with the dentist, performing activities to promote, prevent, cure, and rehabilitate oral health, thus seeking a better quality of life for these patients.

\section{REFERENCES}

1. Shetty V, Kumar J, Hegde A. Breaking the sound barrier. Oral health education for children with hearing impairment. Spec Care Dentist. 2014 May-Jun; 34(3):131-137. doi: 10.1111/scd.12042.

2. Simon EN, Matee MI, Scheutz F. Oral health status of handicapped primary school pupils in Dar es Salaam, Tanzania. East Afr Med J. 2008 Mar; 85(3):113117

3. Tamaskar P, Malia T, Stern C, Gorenflo D, Meador H, Zazove P. Preventive attitudes and beliefs of deaf and hard-of-hearing individuals. Arch Fam Med. 2000 Jun; 9(6):518-526. doi: 10.1001/archfami.9.6.518.

4. Kumar S, Dagli RJ, Mathur A, Jain M, Duraiswamy P, Kulkarni S. Oral hygiene status in relation to sociodemographic factors of children and adults who are hearing impaired, attending a special school. Spec Care Dentist. 2008 Nov-Dec;
28(6):258-264. doi: 10.1111/j.1754-4505.2008.00049.x.

5. Mustafa M, Asiri FYI, AlGhannam S, AlQarni IAM, AlAteeg MA, Anil S. Extent of Awareness Regarding Oral Health and Dental Treatment Needs among Individuals with Hearing and Speech Impairments in Saudi Arabia. J Int Soc Prev Community Dent. 2018 Feb; 8(1):70-76. doi: 10.4103/jispcd.JISPCD_194_17.

6. Sandeep V, Kumar M, Vinay C, Chandrasekhar R, Jyostna P. Oral health status and treatment needs of hearing impaired children attending a special school in Bhimavaram, India. Indian J Dent Res. 2016 Jan-Feb; 27(1): 73-77. doi: 10.4103/0970-9290.179835.

7. Cannobbio VC, Cartes-Velásquez R, McKee M. Oral Health and Dental Care in Deaf and Hard of Hearing Population: A Scoping Review. Oral Health Prev Dent. 2020; 18(3): 417-425. doi: 10.3290/j.ohpd.a44687. 
8. Alkahtani FH, Baseer MA, Ingle NA, Assery MK, Al Sanea JA, AISaffan AD, et al. Oral Health Status, Treatment Needs and Oral Health Related Quality of Life among Hearing Impaired Adults in Riyadh City, Saudi Arabia. J Contemp Dent Pract. 2019 Jun; 20(6): 743-749.

9. G S, Das UM, Bs A. Dentition Status and Oral Health Practice among Hearing and Speech-Impaired Children:A Cross-sectional Study. Int J Clin Pediatr Dent. 2011 May-Aug; 4(2):105-108. doi: 10.5005/jp-journals-10005-1091.

10. Perkins J. EPSDT's Role in Improving Child Vision, Hearing, and Oral Health. J Law Med Ethics. 2017 Mar; 45(1_suppl): 65-68. doi: $10.1177 / 1073110517703328$.

11. Singh A, Agarwal A, Aeran H, Dhawan P. Oral Health \& Quality of Life in preadolescents with hearing impairment in Uttarakhand, India. J Oral Biol Craniofac Res. 2019 Apr-Jun; 9(2): 161-165. doi: 10.1016/j.jobcr.2019.03.004.

12. Vichayanrat T, Kositpumivate W. Oral health conditions and behaviors among hearing impaired and normal hearing college students at Ratchasuda College, Nakhon Pathom, Thailand. Southeast Asian J Trop Med Public Health. 2014 Sep; 45(5):1228-1235.

13. M SB, Deshpande MA, Thosar N, Rathi N, Bane S, Deulkar P. Comparison of impact of oral hygiene instructions given via sign language and validated customized oral health education skit video on oral hygiene status of children with hearing impairment. J Indian Soc Pedod Prev Dent. 2020 Jan-Mar; 38(1): 20-25. doi: 10.4103/JISPPD.JISPPD_37_20.

14. Pollak C, Floy M, Say B. Sensorineural hearing loss and enamel hypoplasia with subtle nail findings: another family with Heimler's syndrome. Clin Dysmorphol. 2003 Jan; 12(1): 55-58. doi: 10.1097/00019605-20030100000010.

15. Hempel E, Limberger K, Möller M, Heinrich-Weltzien R. Mundgesundheit von Erfurter Schüler/innen mit und ohne Behinderungen [Oral health status of students with and without disabilities in Erfurt, Germany]. Gesundheitswesen. 2015 Apr; 77(4): 263-268. doi: 10.1055/s-0034-1377032.

16. Jain M, Bharadwaj SP, Kaira LS, Bharadwaj SP, Chopra D, Prabu D, et al. Oral health status and treatment need among institutionalised hearing-impaired and blind children and young adults in Udaipur, India. A comparative study. Oral Health Dent Manag. 2013 Mar; 12(1): 41-49.

17. Suhani RD, Suhani MF, Muntean A, Mesaros M, Badea ME. Deleterious oral habits in children with hearing impairment. Clujul Med. 2015; 88(3): 403-407. doi: $10.15386 /$ cjmed-453.

18. Jnaneswar A, Subramaniya GB, Pathi J, Jha K, Suresan V, Kumar G. Assessment of dental caries and periodontal status in institutionalized hearing impaired children in Khordha District of Odisha. J Indian Soc Pedod Prev Dent. 2017 Jul-Sep; 35(3):203-208.

19. Sanjay V, Shetty SM, Shetty RG, Managoli NA, Gugawad SC, Hitesh D. Dental health status among sensory impaired and blind institutionalized children aged 6 to 20 years. J Int Oral Health. 2014 Feb; 6(1): 55-58.

20. Sandeep V, Vinay C, Madhuri V, Rao VV, Uloopi KS, Sekhar RC. Impact of visual instruction on oral hygiene status of children with hearing impairment. J Indian Soc Pedod Prev Dent. 2014 Jan-Mar; 32(1): 39-43. doi: 10.4103/09704388.127053

21. Saikiran KV, Kamatham R, Sahiti PS, Nuvvula S. Impact of educational (sign language/video modeling) and therapeutic (Glycyrrhiza glabra--liquorice mouth wash) interventions on oral health pertaining to children with hearing impairment: A randomized clinical trial. Spec Care Dentist. 2019 Sep; 39(5): 505514. doi: $10.1111 /$ scd.12404.

22. Keselyak NT, Simmer-Beck M, Bray KK, Gadbury-Amyot CC. Evaluation of an academic service-learning course on special needs patients for dental hygiene students: a qualitative study. J Dent Educ. 2007 Mar; 71(3): 378-92.

\section{How to cite this article/Como citar este artigo:}

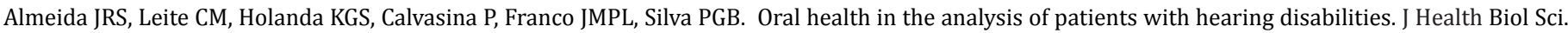
2021; 9(1):1-7. 